\title{
Pernicious repercussion of quack prescribing and Self-medication: A hexagon of cases featuring Cutaneous Adverse Drug Reaction (CADR) in a tertiary care hospital of Eastern India
}

\author{
Bikramjit Barkandaj $^{1}$, Kaushik Mukhopadhyay ${ }^{2}$, Ribhu Chatterjee ${ }^{3}$, Suvajit Das ${ }^{4}$, Chandan Chatterjee ${ }^{5 *}$ \\ ${ }^{1}$ Tutor, ${ }^{2,4}$ Assistant Professor, ${ }^{3}$ Research Scholar, ${ }^{5}$ Associate Professor, ${ }^{\mathbf{1 , 2 5}}$ ESI-PGIMSR, ESIC Medical College and Hospital, Kolkata, \\ West Bengal, ${ }^{3}$ Garden High, ${ }^{4}$ Rampurhat Medical College and Hospital, West Bengal, India
}

*Corresponding Author: Chandan Chatterjee

Email: rivuc2006@gmail.com

\begin{abstract}
In this case series, we are going to present you with half a dozen cases of adverse drug reactions affecting skin, which took place recently in a tertiary care hospital in eastern India. They were contributed to the wrong use of over-the-counter medications due to the incorrect prescribing by the medical shop owners or self-medication. The casual behaviour of the government over 'quack' prescribing and unawareness of common people regarding self-medication may guide to adverse events caused by medical management rather than by an underlying disease which remain undetected by pharmacovigilance programmes. That is why we have decided to analyse series of 6 cases presented in our institution due to self-medication within 14 days.
\end{abstract}

Keywords: Skin, ADR, Quack, Self-Medication.

\section{Introduction}

In our country, we can say that drug dispensed by quack practitioners is quite common. This guide to adverse events caused by medical management rather than by an underlying disease, including treatment using drugs mistakes and ADRs which normally remain ignored. ${ }^{1-3}$ In this case series, we are going to present you with half a decade of cases about ADRs effecting skin, \{Cutaneous Adverse Drug Reactions (CADR) $\}$ which took place recently in a tertiary care hospital of eastern India. They were a result of medications due to the incorrect drug dispensing by the medical shop owners or self-medication.

\section{Case Description}

\section{Case report 1}

A rural boy presented with few lesions (urticaria) in the upper extremity. (Fig. 1) He reported of being prescribed metronidazole by a prescriber-cum-medical shop owner. He was not on any other medications and no history of similar incident in the past. The drug was withdrawn after few days in an outdoor tertiary medical centre and an antihistaminic medication was advised.

\section{Case report 2}

A 16-year old male patient in class 10 was suffering from hypopigmentation on cutaneous regions of the face. He had been on clobetasol propionate $(0.5 \%$ cream) for 3 months (Self-medication) (Fig. 2) $\mathrm{He}$ was advised to stop medications and normal saline was given to get rid of irritation along with cetirizine tablet $(10 \mathrm{mg})$ for 2 weeks. ${ }^{4}$

\section{Case report 3}

A female patient aged 35 presented with multiple hyperpigmented lesions on the upper extremity which developed following a prescription of metronidazole due to diarrhoea from a quack practitioner. Patient complained of similar type of lesions 4 times in her lifetime in the same spot following self-medication of metronidazole and diagnosed as a case of fixed drug reaction (FDR) in our outdoor. (Fig. 3) She was advised not to take metronidazole anymore and topical mometasone $(0.5 \%)$ cream was prescribed as treatment.

\section{Case report 4}

A 35 year old male patient presented with toxic epidermal necrosis following over the counter prescription of antibiotic (combination of amoxicillin and clavulanic acid). (Fig. 4) Patient also received nimesulide from the same shop on the same day and hence it was difficult to pinpoint the culprit as re-challenge test was not ethically permitted. He was admitted and recovered completely after being treated in ICCU and indoor with cyclosporine, ceftriaxone and proper water and electrolyte management.

\section{Case report 5}

The fifth case was one of a middle aged man, a bus conductor by occupation, was prescribed ibuprofen for managing pain around his knee joint. He developed severe itching and exfoliative dermatitis involving almost $3 / 5$ of his body. (Fig. 5) Patient was assured, drug was stopped and treatment was started with levocetrizine $(10 \mathrm{mg})$, betamethasone valerate $(0.05 \%)$ cream and a moisturiser. All basic investigations were normal.

\section{Case report 6}

20- year old lady presented with Allergic contact dermatitis following self-application of Dettol (chloroxylenol) after an insect bite.(Fig. 6) Initially it was benign in nature, and a right side of neck was involved. It became itchy, and selfmedication with Dettol aggravated the condition. Dettol was stopped and oral steroid prednisolone $40 \mathrm{mg}$ and levocetrizine $5 \mathrm{mg}$ were prescribed to give her relief. 


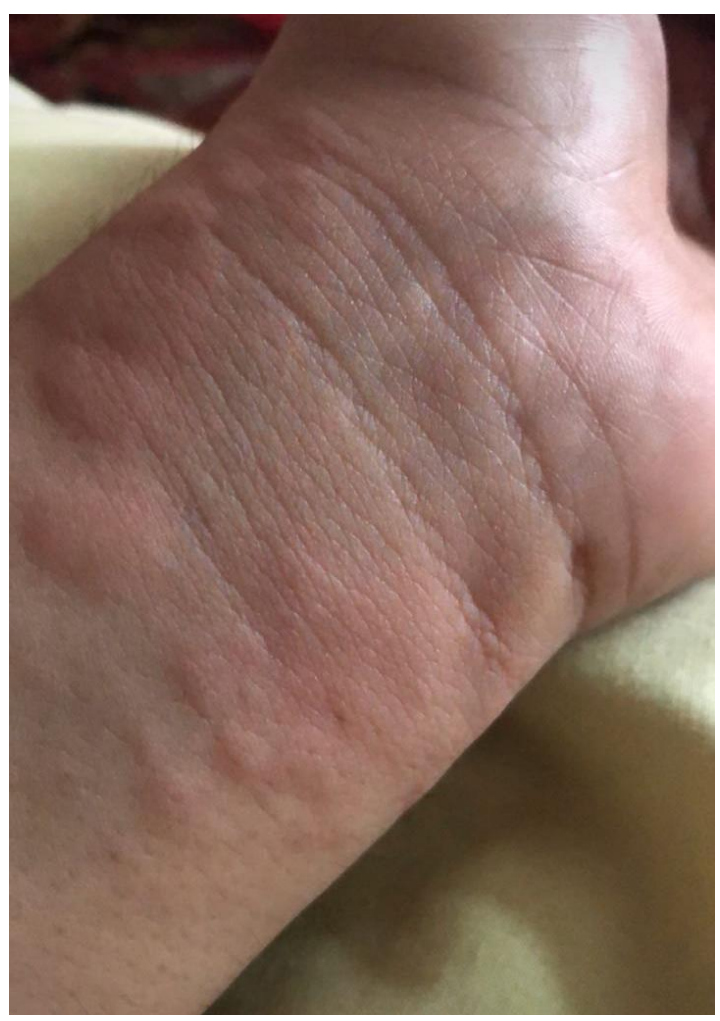

Fig. 1: Urticarial lesions on left upper extremity



Fig. 2: Hypopigmented lesions on left side of face

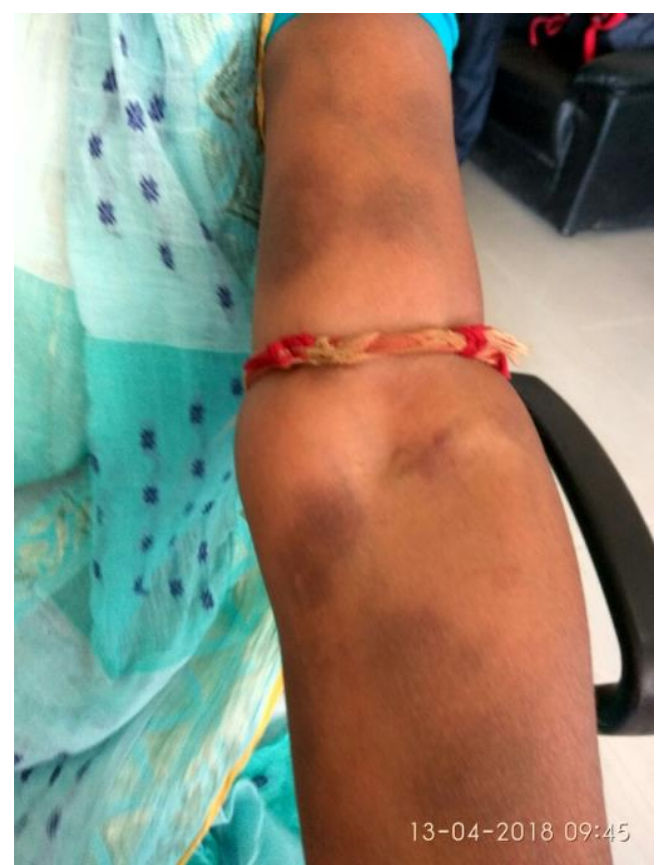

Fig. 3: Fixed drug reactions on right upper extremity

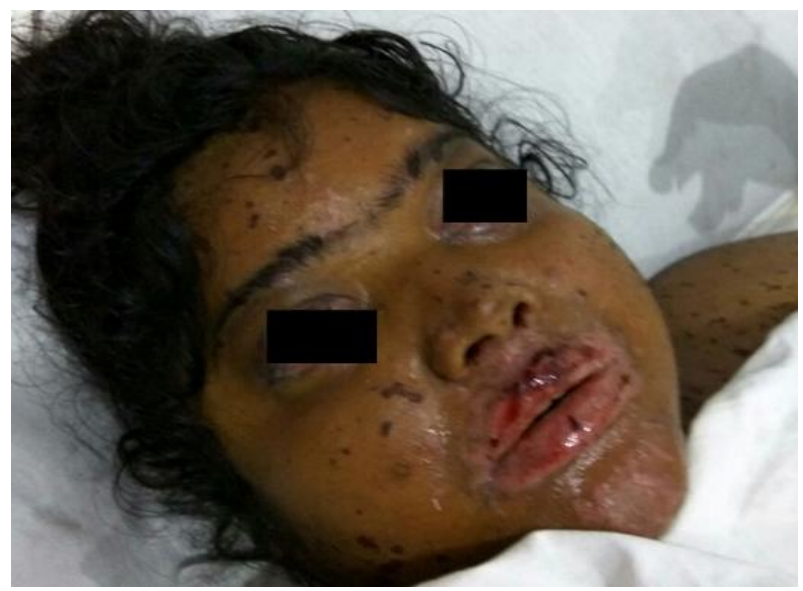

Fig. 4: A case of Toxic epidermal necrolysis 


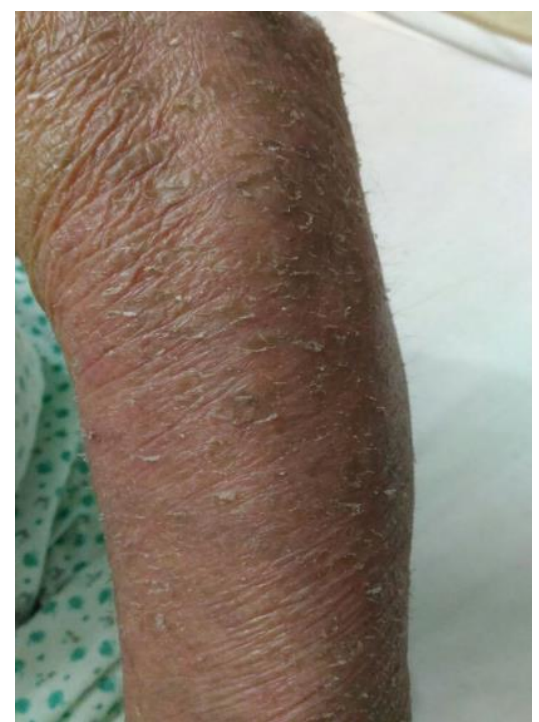

Fig. 5: Exfoliative dermatitis

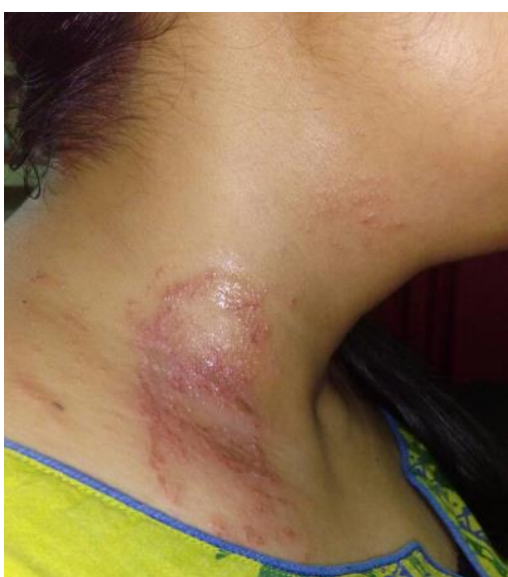

Fig. 6: Allergic contact dermatitis due to Dettol (chloroxylenol) on right side of the neck

\section{Results}

Total number of cases reported in that span was 14 . Out of that 6 cases happened due to self medication or quack prescribing scored between 6 to 8 and showed a probable causation using Naranjo ADR Probability Scale. (Table 1,2) WHO causality assessment scale had also shown similar results. Due to ethical reason re-challenge test was not performed in any of these 6 cases. Two (2) of them were topical preparations whereas the other preparations were oral tablets. 4 out of 6 were male and rest were female patients.

Table 1: Causality assessment of using naranjo adr probability scale for all 6 cases

\begin{tabular}{|c|c|c|c|}
\hline & Naranjo Causality Assessment Scale & Case Report 1,2,3 & Case Report 4,5,6 \\
\hline 1 & $\begin{array}{l}\text { Are there previous conclusive reports on this reaction? } \\
\text { Yes }(+1) \text { No }(0) \text { Do not know or not done }(0)\end{array}$ & $1,1,1$ & $1,1,1$ \\
\hline 2 & $\begin{array}{l}\text { Did the AE appear after the suspected drug was given? } \\
\text { Yes (+2) No (-1) Do not know / Not done (0) }\end{array}$ & $2,2,2$ & $2,2,2$ \\
\hline 3 & $\begin{array}{l}\text { Did the adverse reaction improve when the drug was discontinued or a } \\
\text { specific antagonist was given? } \\
\text { Yes }(+1) \text { No (0) Do not know or not done ( } 0)\end{array}$ & $1,1,1$ & $1,1,1$ \\
\hline 4 & $\begin{array}{l}\text { Did the adverse reaction appear when drug was readministered? Yes (+2) } \\
\text { No (-1) Do not know / Not done }(0)\end{array}$ & $0,0,0$ & $0,0,0$ \\
\hline 5 & $\begin{array}{l}\text { Are there alternative causes that could have caused the reaction? Yes }(-1) \\
\text { No }(+2) \text { Do not know or not done }(0)\end{array}$ & $2,2,2$ & $2,2,2$ \\
\hline 6 & $\begin{array}{l}\text { Did the reaction reappear when a placebo was given? Yes }(-1) \\
\text { No }(+1) \text { Do not know or not done }(0)\end{array}$ & $0,0,0$ & $0,0,0$ \\
\hline 7 & $\begin{array}{l}\text { Was the drug detected in any body fluid in toxic concentrations? Yes }(+1) \\
\text { No }(0) \text { Do not know or not done }(0)\end{array}$ & $0,0,0$ & $0,0,0$ \\
\hline 8 & $\begin{array}{l}\text { Was the reaction more severe when the dose was increased, or less severe } \\
\text { when the dose was decreased? Yes }(+1) \text { No }(0) \text { Do not know or not done }(0)\end{array}$ & $0,0,0$ & $0,0,0$ \\
\hline 9 & $\begin{array}{l}\text { Did the patient have a similar reaction to the same or similar drugs in any } \\
\text { previous exposure? Yes }(+1) \text { No }(0) \text { Do not know or not done }(0)\end{array}$ & $0,0,1$ & $0,0,0$ \\
\hline 10. & $\begin{array}{l}\text { Was the adverse event confirmed by any objective evidence? Yes }(+1) \\
\text { No }(0) \text { Do not know or not done }(0)\end{array}$ & $0,0,0$ & $0,0,0$ \\
\hline $\begin{array}{l}\text { Tota } \\
\text { less) }\end{array}$ & I Score (Definite: 9 or higher / Probable: 5 to 8 / Possible: 1 to 4 / Doubtful - 0 or & $6,6,7$ & $6,6,6$ \\
\hline$I_{n}$ & & Probs & \\
\hline
\end{tabular}

\begin{tabular}{|c|c|c|c|c|}
\hline $\begin{array}{c}\text { Total no of ADR } \\
\text { reported within 14 days }\end{array}$ & $\begin{array}{c}\text { Cases due to unauthorised } \\
\text { prescribing and self- } \\
\text { medication }\end{array}$ & $\begin{array}{c}\text { \% of case due to } \\
\text { unauthorised prescribing } \\
\text { and self-medication }\end{array}$ & $\begin{array}{c}\text { Recovery of } \\
\text { cases }\end{array}$ & Reporting of cases \\
\hline 6 & 6 & $43 \%$ & $100 \%$ & $100 \%$ \\
\hline
\end{tabular}




\section{Discussion}

We came across 14 cases out of which 6 similar cases were related to unauthorised prescribing and self -medication which commonly ended up in adverse drug reactions affecting skin. These incidents would not have taken place if there was no wrong prescribing fed to the customers. These CADRs came to our attention accidentally. Now, all the patients are taken care of under the supervision of the doctors. The reactions are settling, although we do not know about their epilogues. ${ }^{5,6}$ WHO causality assessment scale had also shown similar results as Narango scale. ${ }^{7,8}$ These incidents may have put forward a defect in the primary mode of operation of case detection of pharmacovigilance schedule, whereby homogeneous occasions of unofficial prescribing related adverse events caused by medical management go ignored in India. Till now, the right to give an account of ADRs was only confined to doctors, nurses and druggists. Presently, even when the public delineating of ADRs is being inspired, the expectations of a quack practitioner being trained to report such examples of adverse drug events are improbable, the cause being too prominent. Nevertheless, legally criticizing over the counter (OTC) prescribing is now not an option as there is a shortage of public section major care doctors in India. Substantial attention should be paid by the federal pharmacovigilance program regarding the detecting cases of irrational prescribing which are guilty of causing otherwise avoidable drug related issues. The deficiency of universal recognition among the stack regarding the harmful consequences of quack prescribing requires to be properly labelled. Doctors and bonesetters should remain watchful and proactively prevent unofficial prescribing and similar misfortunes.

\section{Source of funding}

None.

\section{Conflict of interest}

None.

\section{References}

1. Suvajit Das, Kaushik Mukhopadhyay, Sudipta Kumar Dey, Sonali Mukherjee, Chandan Chatterjee. The inimical Repercussions of unauthorised Prescribing: Binary Reports Featuring Cutaneous Adverse Drug Reaction. Indian J Pharm Pharmacol 2015;2:236-40.

2. Mhatre SK, Sansgiry SS. Assessing a conceptual model of over-the-counter medication misuse, adverse drug events and health-related quality of life in an elderly population. Geriatr Gerontol Int 2015 Jan 22. doi: 10.1111/ggi.12443

3. Yu YM, Shin WG, Lee JY, Choi SA, Jo YH, Youn SJ, et al. Patterns of Adverse Drug Reactions in Different Age Groups: Analysis of Spontaneous Reports by Community Pharmacists PLoS One. 2015;10(7).

4. Arijit Coondoo, Meghana Phiske, Shyam Verma, Koushik Lahiri. Side-effects of topical steroids: A long overdue revisit. Indian Dermatol Online J 2014;5:416-25.

5. Peter O. Fritsch, Ramon Ruiz-Maldonado; Erythema Multiforme, Stevens-Johnson Syndrome, and Toxic Epidermal Necrolysis; Fitzpatrick's Dermatology in General Medicine; Vol 1. Sixth Edition, The McGraw Hill,2003;543-56.

6. S.M. Breathnach, Erythema Multiforme, Stevens Johnson Syndrome and Toxic Epidermal Necrolysis. Rook's Textbook of Dermatology. Vol.4, Seventh Edition. Blackwell Publishing, 2004:74.1-74.

7. Naranjo CA. A method for estimating the probability of adverse drug reactions. Clin Pharmacol Ther 198130: 239245.

8. The use of the WHO-UMC system for standardised case causality assessment, available from http://whoumc.org/Graphics/24734.pdf, accessed on 20th Nov., 2015

How to cite this article: Barkandaj B, Mukhopadhyay K, Chatterjee R, Das S, Chatterjee C. Pernicious repercussion of quack prescribing and Self-medication: A hexagon of cases featuring Cutaneous Adverse Drug Reaction (CADR) in a tertiary care hospital of Eastern India. Indian J Pharm Pharmacol 2019;6(3):103-6. 